Article

\title{
Fresh and Cryopreserved Human Umbilical-Cord-Derived Mesenchymal Stromal Cells Attenuate Injury and Enhance Resolution and Repair following Ventilation-Induced Lung Injury
}

\author{
Shahd Horie ${ }^{1,2}$, Hector Gonzalez ${ }^{1,2, \dagger}$, Jack Brady ${ }^{1,2, \dagger}$, James Devaney ${ }^{1,2, \ddagger}$, Michael Scully ${ }^{1,3}$, \\ Daniel O'Toole ${ }^{1,2, *, \S}$ and John G. Laffey $1,2,3,4, *, \S(\mathbb{D}$
}

1 Anaesthesia, School of Medicine, Clinical Sciences Institute, National University of Ireland, H91 TK33 Galway, Ireland; shahd.horie@nuigalway.ie (S.H.); h.gonzalez2@nuigalway.ie (H.G.); J.BRADY8@nuigalway.ie (J.B.); jamesdevaney@gmail.com (J.D.); michael.scully@nuigalway.ie (M.S.)

2 Regenerative Medicine Institute (REMEDI), CÚRAM Centre for Research in Medical Devices, National University of Ireland Galway, Biomedical Sciences Building, H91 TK33 Galway, Ireland

3 Medicine, School of Medicine, Clinical Sciences Institute, National University of Ireland, H91 TK33 Galway, Ireland

4 Department of Anaesthesia, Galway University Hospitals, SAOLTA University Health Group, H91 YR71 Galway, Ireland

Citation: Horie, S.; Gonzalez, H.; Brady, J.; Devaney, J.; Scully, M.; O'Toole, D.; Laffey, J.G. Fresh and Cryopreserved Human

Umbilical-Cord-Derived

Mesenchymal Stromal Cells Attenuate Injury and Enhance Resolution and Repair following Ventilation-Induced Lung Injury. Int. J. Mol. Sci. 2021, 22, 12842. https:// doi.org/10.3390/ijms222312842

Academic Editor: Arianna Scuteri

Received: 22 October 2021

Accepted: 26 November 2021

Published: 27 November 2021

Publisher's Note: MDPI stays neutral with regard to jurisdictional claims in published maps and institutional affiliations.

Copyright: (c) 2021 by the authors. Licensee MDPI, Basel, Switzerland. This article is an open access article distributed under the terms and conditions of the Creative Commons Attribution (CC BY) license (https:/ / creativecommons.org/licenses/by/ $4.0 /)$.
* Correspondence: daniel.otoole@nuigalway.ie (D.O.); john.laffey@nuigalway.ie (J.G.L.)

+ Hector Gonzalez and Jack Brady contributed equally to this work.

$\ddagger$ James Devaney is deceased.

$\S$ Daniel O'Toole and John G. Laffey have joint senior authorship.

\begin{abstract}
Background: Ventilator-induced lung injury (VILI) frequently worsens acute respiratory distress syndrome (ARDS) severity. Human mesenchymal stem/stromal cells (MSCs) offer considerable therapeutic promise, but the key impediments of clinical translation stem from limitations due to cell source and availability, and concerns regarding the loss of efficacy following cryopreservation. These experiments compared the efficacy of umbilical-cord-derived MSCs (UC-MSCs), a readily available and homogenous tissue source, to the previously more widely utilised bone-marrow-derived MSCs (BM-MSCs). We assessed their capacity to limit inflammation, resolve injury and enhance repair in relevant lung mechanical stretch models, and the impact of cryopreservation on therapeutic efficacy. Methods: In series 1, confluent alveolar epithelial layers were subjected to cyclic mechanical stretch (22\% equibiaxial strain) and wound injury, and the potential of the secretome from BM- and UC-derived MSCs to attenuate epithelial inflammation and cell death, and enhance wound repair was determined. In series 2, anesthetized rats underwent VILI, and later received, in a randomised manner, $1 \times 10^{7}$ MSCs/kg intravenously, that were: (i) fresh BM-MSCs, (ii) fresh UC-MSCs or (iii) cryopreserved UC-MSCs. Control animals received a vehicle (PBS). The extent of the resolution of inflammation and injury, and repair was measured at $24 \mathrm{~h}$. Results: Conditioned medium from BM-MSCs and UC-MSCs comparably decreased stretch-induced pulmonary epithelial inflammation and cell death. BM-MSCs and UC-MSCs comparably enhanced wound resolution. In animals subjected to VILI, both fresh BM-MSCs and UC-MSCs enhanced injury resolution and repair, while cryopreserved UC-MSCs comparably retained their efficacy. Conclusions: Cryopreserved UC-MSCs can reduce stretch-induced inflammation and cell death, enhance wound resolution, and enhance injury resolution and repair following VILI. Cryopreserved UC-MSCs represent a more abundant, cost-efficient, less variable and equally efficacious source of therapeutic MSC product.
\end{abstract}

Keywords: acute respiratory distress syndrome; ventilation-induced lung injury; injury; mesenchymal stem/stromal cells; cryopreservation; tissue source 


\section{Introduction}

Mesenchymal stem/stromal cells (MSCs) show promise as a therapeutic strategy for sepsis and acute respiratory distress syndrome (ARDS). MSCs were observed to modulate the inflammatory process, improve alveolar epithelial barrier function, attenuate lung injury and reduce the overall mortality in diverse preclinical sepsis and ARDS animal models [1-7], including our model of E. coli-induced pneumonia [8,9] and repair from ventilator-induced lung injury (VILI) [10]. VILI is an inflammatory process that can result from certain mechanical ventilation strategies, which are necessary to ensure adequate oxygenation but often worsen ARDS. The mechanisms of action of MSCs in VILI are numerous, including the secretion of a range of paracrine mediators and microparticles that can ameliorate the evolution of injury and inflammation, as well as promote tissue repair and recovery [11]. Importantly, MSCs demonstrate utility in human lungs ex vivo [12], and MSCs are well tolerated, showing promising efficacy in a number of phase I/phase II clinical trials [13].

As early phase trials progress, three key issues in relation to the clinical translation of MSCs have been highlighted which are the source of the cell, the protocol of cell expansion, and the mechanism of storage and transport. The industrialization of bone marrow (BM) MSC production for large-scale phase III clinical trials necessitates extensive culture expansion from each bone marrow donation in order to secure suitable doses for systemic delivery [14]. MSCs, which are expanded in cultures, exhibit telomere shortening, which is one factor causative of senescence and an eventual form of cell exhaustion and cessation of proliferation. $[15,16]$. Other expansion protocol factors can also contribute to phenotypic changes in the cell therapy which could diminish efficacy, reduce cell longevity after engraftment and hamper their regenerative and immunomodulatory properties [16].

The human umbilical cord is a rich source of MSCs and preparing them from this tissue has many obvious advantages when compared to the traditional alternatives. These advantages are particularly clear with regard to the production volumes of the MSCs without introducing senescence. The umbilical cord is also easily procured, as it is a waste tissue where harvesting does not require any sort of invasive procedure as with bone marrow or adipose MSCs. From one donor, the umbilical cord can produce more early-passage MSCs (by one order of magnitude) than a typical bone marrow donation, instead facilitating the manufacturing of large quantities of the lower-passage MSCs to provide the greatest immunomodulatory capacity [17]. Due to the age of their source, all UC-MSCs are essentially the same age, which increases the homogeneity of the final cell product, enhancing reproducibility in the recipient [18].

Finally, the majority of previous studies using MSCs use them as harvested directly from culture, but this approach may only be of utility for chronic diseases and even then is of reduced practicality. It remains to be conclusively proven whether efficacy is retained when MSCs are administered immediately following cryopreservation; therefore, this is a critical step on the translational path. Differences in MSC characteristics, particularly their immune modulation capabilities, were linked to their source of origin and cryopreservation status and, as such, direct comparison studies are required [19-22].

We hypothesised that UC-MSCs would modulate inflammation and enhance repair after VILI, in a comparable manner to the "gold standard" BM-MSCs, and that cryopreservation would not alter MSC efficacy.

\section{Results}

\subsection{Cyclic Stretch-Induced Epithelial Injury In Vitro}

Resolution of In Vitro Stretch Injury: $120 \mathrm{~h}$ of mechanical cyclic stretch caused a significant induction of the NFKB transcription factor $(p<0.001)$ and a significant decrease in the viability of alveolar epithelial cells $(p<0.001)$ (Figure 1$)$. BM-MSC conditioned medium (CM) significantly attenuated NFKB activation $(p<0.05)$, as did UC-MSC CM $(p<0.01)$ (Figure 1A). Both BM-MSC CM and UC-MSC CM significantly reversed the decrease in cell viability $(p<0.05)$ in comparison to the DF CM control (Figure 1B). 

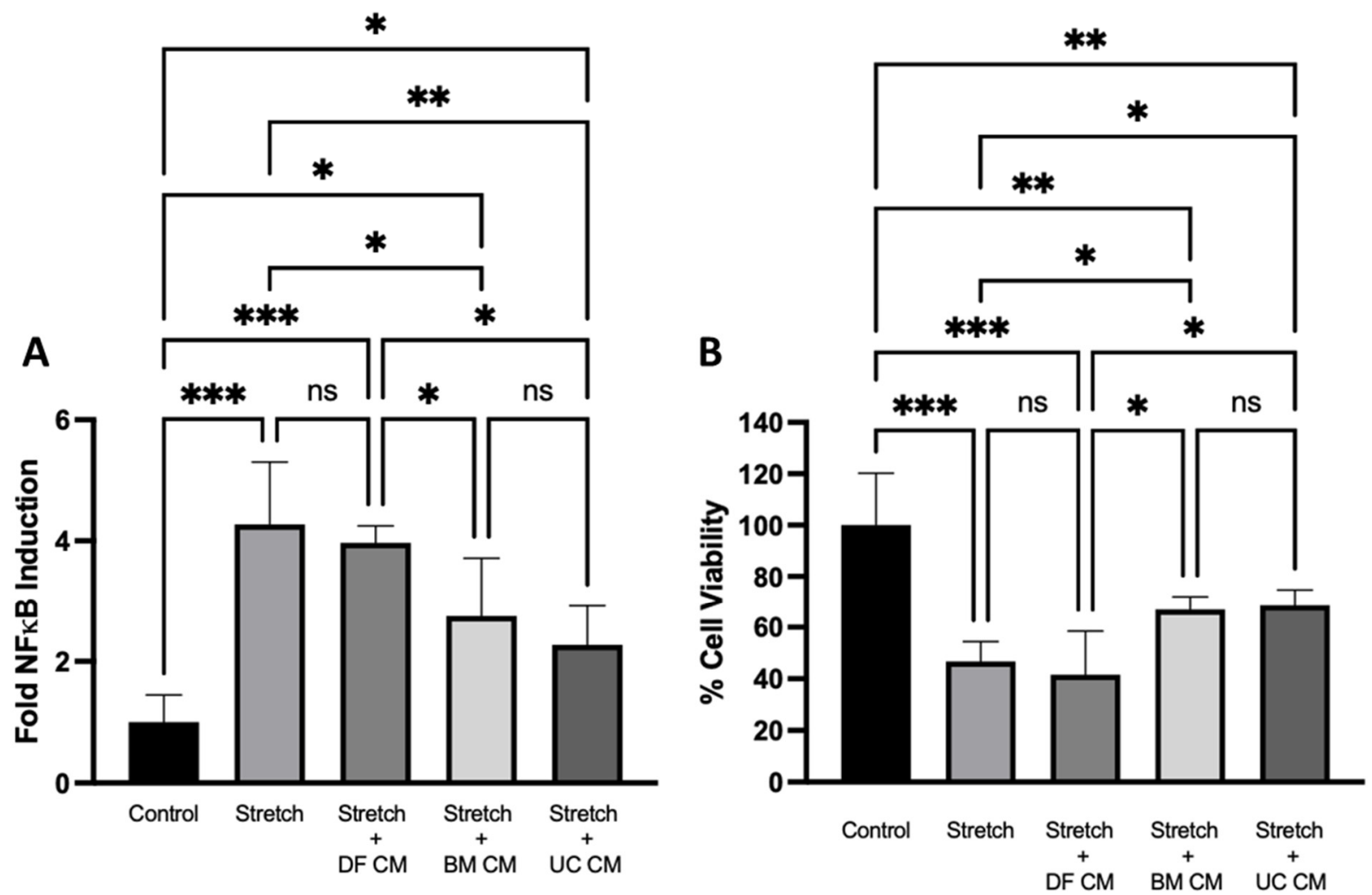

Figure 1. UC-MSC CM attenuates stretch injury in vitro. Stretch-induced $\mathrm{NF}_{\kappa} B$ induction in alveolar epithelial cells was significantly reduced with BM-MSC CM and UC-MSC CM (A). The stretch-induced decrease in cell viability was also ameliorated with BM-MSC CM and UC-MSC CM treatment (B). Note: ${ }^{*},{ }^{* *},{ }^{* * *}=p<0.05,0.01,0.001$, respectively. ns $=$ not significant. $n=3-5$ per group. Control $=$ Non-stretched cells in MEM- $\alpha$ medium. Stretch $=$ stretched cells in MEM- $\alpha$ medium. Stretch + DF CM = stretched cells in Dermal Fibroblast CM. Stretch + BM CM = stretched cells in BM-MSC CM. Stretch + UC CM = stretched cells in UC-MSC CM.

\subsection{Pulmonary Epithelial Wound Healing In Vitro}

Wound Healing: Treatment with BM-MSC CM or UC-MSC CM significantly enhanced wound restitution in alveolar epithelial cells following scratch wounding in vitro, when compared to the MEM- $\alpha$ control $(p<0.001)$ and DF CM control $(p<0.01$ and 0.05 , respectively) (Figure 2).

\subsection{Injury Resolution Following In Vivo Ventilation-Induced ARDS}

Recovery of Lung Function: VILI caused a significant decrement in oxygenation, lung compliance and lung permeability compared to protective ventilation (Figure 3). Both fresh BM-MSCs and UC-MSCs restored arterial oxygenation $(p<0.001)$ (Figure 3A) when compared to the vehicle (PBS) control group. Importantly, thawed, cryopreserved UC-MSCs also restored arterial oxygenation $(p<0.001)$, demonstrating that these cells retained efficacy post cryopreservation. The decrement in static lung compliance induced by VILI was restored by BM-MSCs and UC-MSCs ( $p<0.001$ and 0.01 , respectively), while thawed, cryopreserved UC-MSCs were similarly effective $(p<0.01)$ (Figure 3B). BM-MSCs and UC-MSCs increased the restoration of alveolar barrier permeability, as shown by a reduction in the lung wet:dry weight ratio ( $p<0.01$ and 0.05 , respectively) (Figure $3 C$ ) and a reduction in the accumulated total protein in the airspace $(p<0.01)$ (Figure 3D). The thawed cryopreserved UC-MSCs retained their efficacy and also restored alveolar fluid clearance $(p<0.05)$ and protein concentrations $(p<0.01)$ to normal levels. 


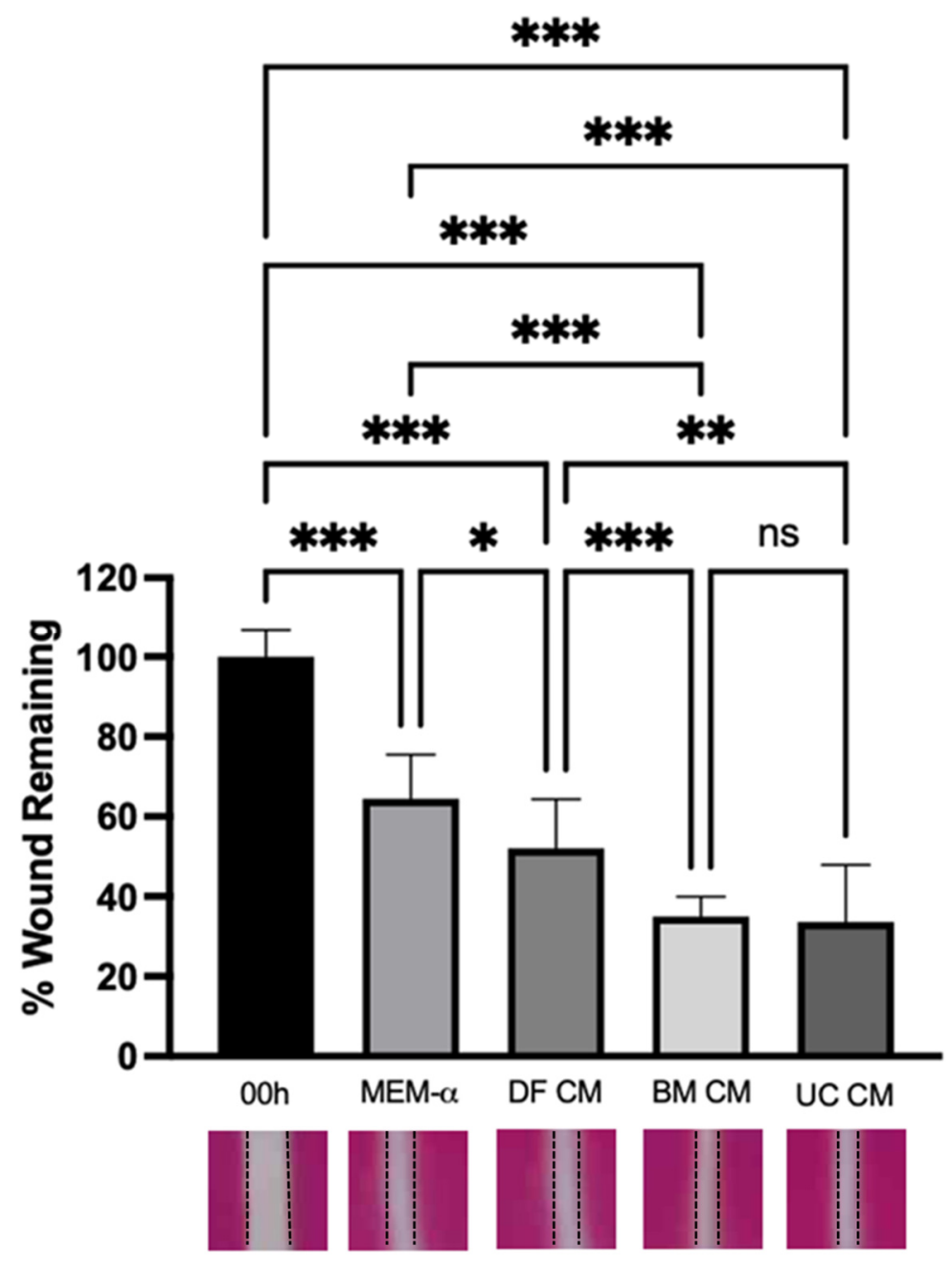

Figure 2. UC-MSC CM accelerates repair following wound injury in vitro. BM-MSC CM and UC-MSC CM significantly enhanced wound closure in vitro, in comparison to MEM- $\alpha$ and DF CM controls. Note: ${ }^{*}, * *, * * * p<0.05,0.01,0.001$, respectively. ns $=$ not significant. $n=3-5$ per group. $00 \mathrm{~h}=$ Time $0 \mathrm{~h}$, at which scratch wounds were implemented. MEM- $\alpha=$ scratched layers in MEM- $\alpha$ medium at $48 \mathrm{~h}$. DF CM = scratched layers in DF CM at $48 \mathrm{~h}$. BM CM = scratched layers in BM-MSC $\mathrm{CM}$ at $48 \mathrm{~h}$. UC CM = scratched layers in UC-MSC CM at $48 \mathrm{~h}$.

Modulation of the Inflammatory Response: VILI caused a significant inflammatory response (Figure 4). Fresh BM-MSCs and both fresh and cryopreserved UC-MSCs comparably decreased alveolar cell counts ( $p<0.01,0.05$ and 0.01, respectively) (Figure 4A) and alveolar neutrophil counts $(p<0.01)$ (Figure 4B) when compared to the vehicle (PBS) control group. IL-6 release, induced following VILI, was significantly attenuated by fresh BM-MSCs $(p<0.05)$ (Figure 4C). While IL-6 concentrations were lower in the BAL of animals that received freshly delivered UC-MSCs, this was not statistically significant (Figure 4C). In contrast, thawed, cryopreserved UC-MSCs reduced alveolar IL-6 concentrations $(p<0.05$ (Figure 4C). All MSC treatment groups demonstrated significantly reduced alveolar IL- $1 \beta$ concentrations ( $p<0.001,0.01$ and 0.001 , respectively) when compared to the control group (Figure 4D).

Restoration of Lung Structure: VILI caused significant alveolar epithelial structural damage. Treatment with BM-MSCs and UC-MSCs, whether fresh or following cryopreservation, significantly enhanced the restoration of lung histologic structure post VILI $(p<0.001)$, depicted as percentage airspace (Figure 5A) and the amelioration of interstitial and alveolar inflammatory cell infiltration (Figure 5B). 

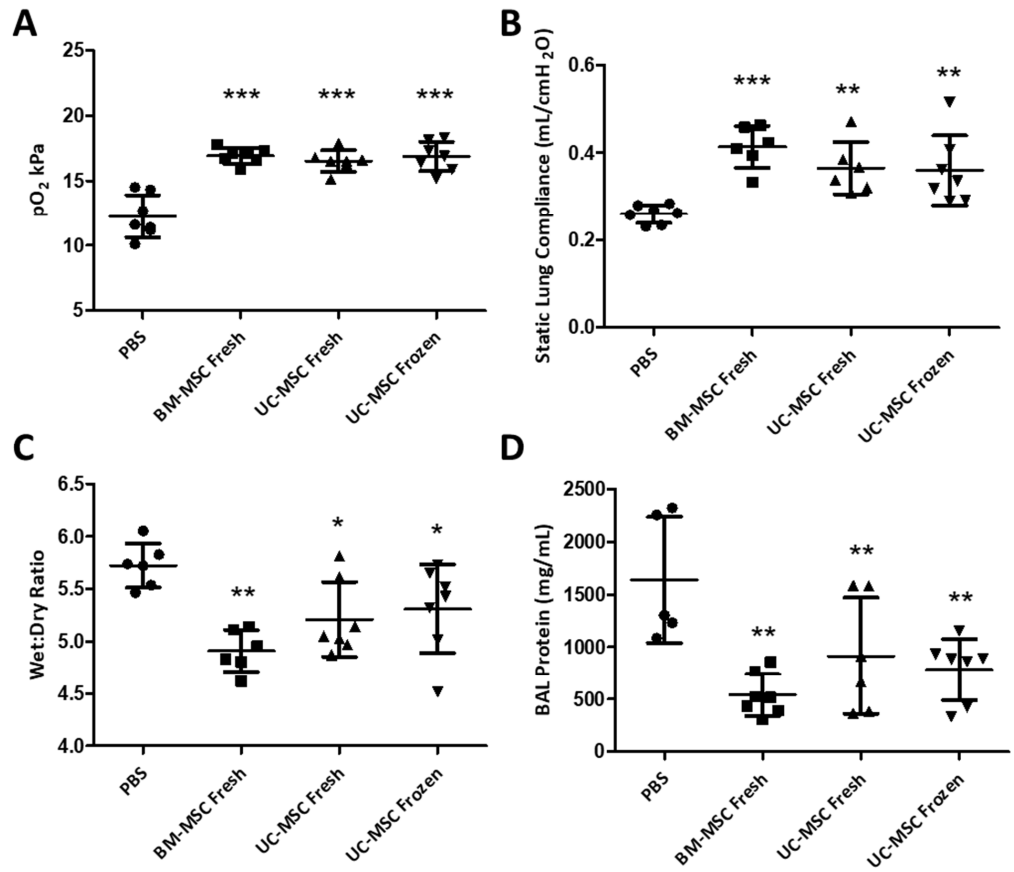

Figure 3. Cryopreserved UC-MSCs restore lung function and the permeability barrier post VILI. BM-MSCs and UC-MSCs comparably restored arterial oxygen (A) as did thawed cryopreserved UC-MSCs (A). The decrease in static lung compliance was also restored by both cell sources (B) while thawed cryopreserved UC-MSCs retained their efficacy (B). Alveolar fluid clearance as depicted by lung wet:dry ratio and BAL protein concentrations was significantly restored by both BM-MSCs and UC-MSCs (C,D), while thawed, cryopreserved UC-MSCs were comparably efficacious (C,D). Note: $*^{* *}, * * *=p<0.05,0.01,0.001$, respectively versus PBS control groups. $n=7$ animals per group.

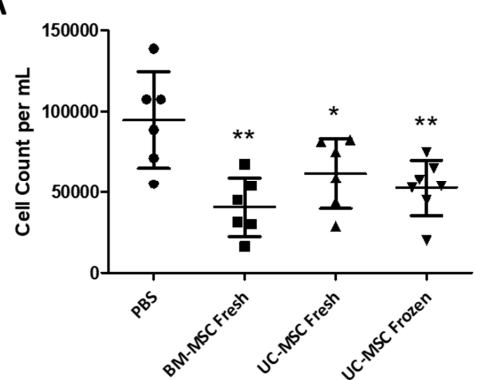

C

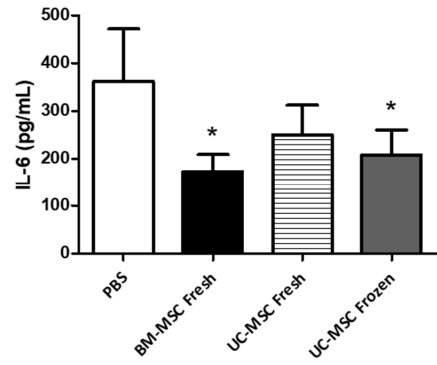

B

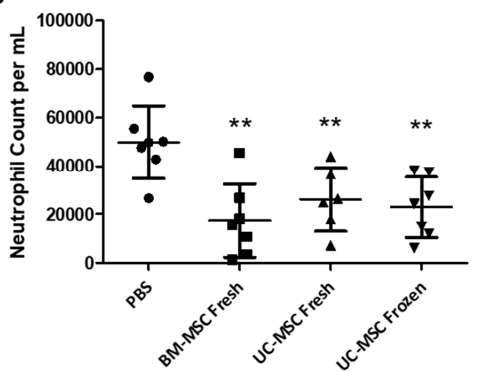

D

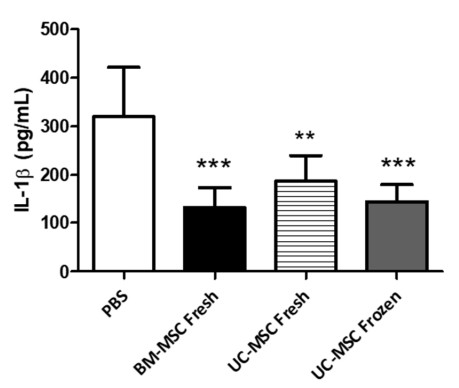

Figure 4. Cryopreserved UC-MSCs modulate inflammatory cell influx and cytokine release. All cell treatment groups significantly resolved cell and neutrophil infiltration into the lung $(\mathbf{A}, \mathbf{B})$ while cryopreserved UC-MSC treatment was comparable in efficacy (A,B). Fresh BM-MSCs and thawed, cryopreserved UC-MSCs significantly attenuated BAL IL-6 (C) when compared to PBS control. All cell treatments ameliorated BAL IL-1 $\beta$ levels (D). Note: ${ }^{*}{ }^{* *},{ }^{* *}=p<0.05,0.01,0.001$, respectively, versus PBS control groups. $n=7$ animals per group. 
A
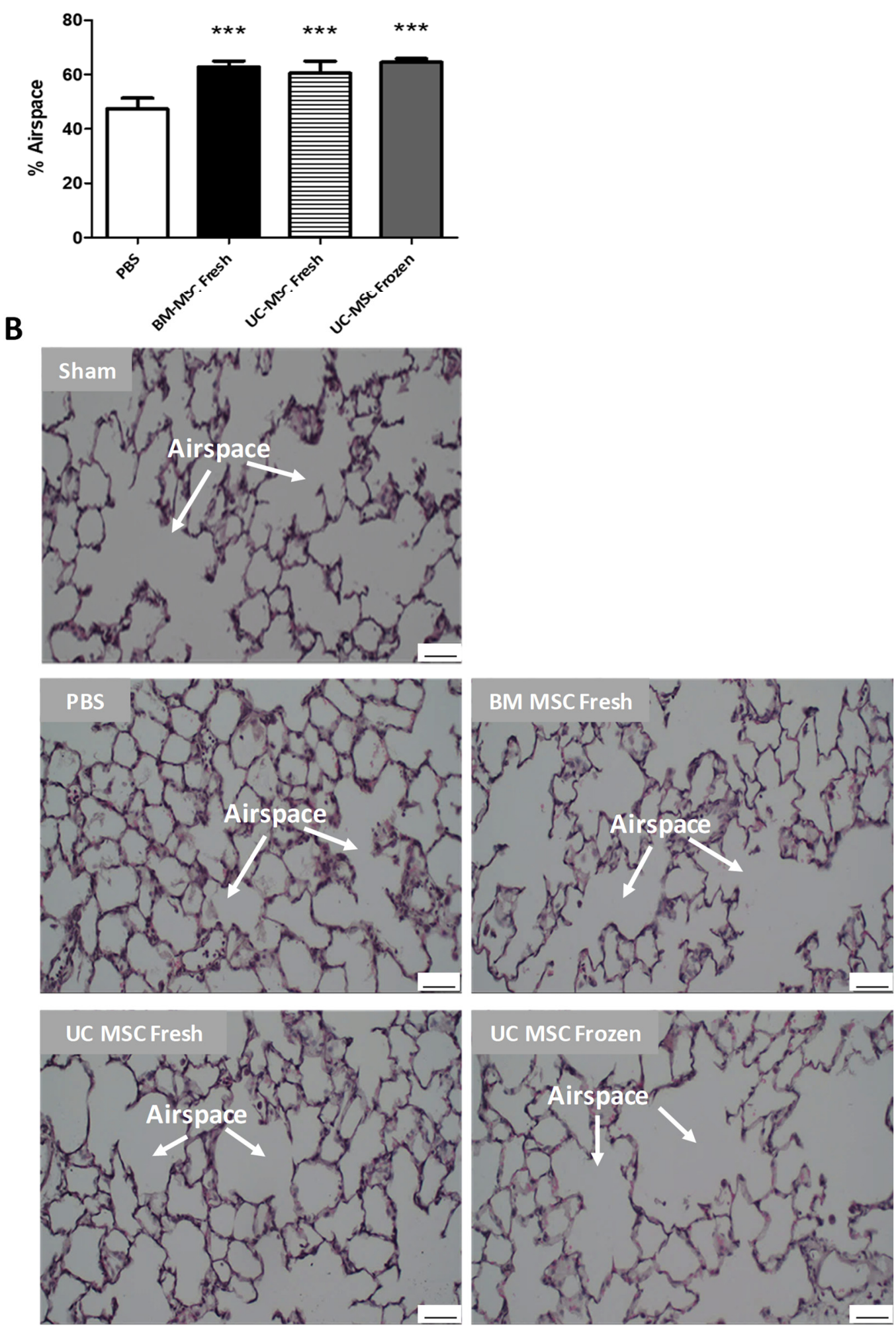

Figure 5. Cryopreserved UC-MSCs restore lung histologic structure. Fresh BM-MSCs and fresh UC-MSCs comparably restored alveolar airspace when compared to PBS control (A). Thawed, cryopreserved UC-MSCs restored lung structure with similar efficacy (A). Representative images of alveolar structure and airspace are depicted above (B). Note: ${ }^{* * *}=p<0.001$ versus PBS control. $n=4$ animals per group. Sham = healthy uninjured control. PBS = animals that received PBS. BM MSC Fresh and UC MSC Fresh = animals that received freshly cultured BM-MSCs or UC-MSCs, respectively. UC MSC Frozen $=$ animals that received cryopreserved UC-MSCs. Scale bar is 50 microns. 


\section{Discussion}

This study demonstrates several novel findings and concludes that UC-MSCs are comparably effective to the "gold standard" BM-MSCs for enhancing repair in the injured epithelium and lung and that UC-MSCs retain efficacy when delivered thawed, post cryopreservation. These findings have important implications for the translation and production of MSC therapies.

\subsection{The Secretome of UC-MCS and BM-MSCs Comparably Rescues the Injured Lung Epithelium}

Treatment with the secretome of either BM-MSCs or UC-MSCs comparably attenuated mechanical stretch injury and enhanced repair following wound injury in vitro. Similar findings were observed in previous studies $[8,10]$ and this further supports the hypothesis that the mechanism of therapeutic action of MSCs involves, in part, the release of paracrine mediators.

\subsection{UC-MSCs and BM-MSCs Comparably Restore Lung Function}

This study demonstrated for the first time, that UC-MSCs are comparably efficacious to BM-MSCs, in restoring oxygenation and compliance in a rat model of recovery following VILI. We previously reported this finding for fresh BM-MSCs in VILI [23], but this is the first study to directly compare the efficacy of BM-MSCs to UC-MSCs in this preclinical model. This study also observed that UC-MSCs retained their efficacy to achieve the aforementioned effects after cryopreservation, which is a significant advance for clinical translation in terms of production and delivery. Previous studies reported that cryopreserved BM-MSCs were efficacious in restoring oxygenation and compliance in a rat model of pneumonia [8] and this can be considered alongside the findings of this study to further support the use of cryopreserved MSCs.

Administration of either BM-MSCs or UC-MSC cells was also comparable in the restoration of alveolar membrane integrity, as both treatments were shown to equally restore alveolar fluid clearance and reduce protein concentration in the injured lung. The administration of BM-MSCs was previously shown to lower protein concentrations and fluid retention in the lungs of animals with VILI, but this study is the first to obverse these findings for UC-MSCs in VILI. Furthermore, cryopreservation did not hinder the efficacy of UC-MSCs to restore alveolar membrane integrity following VILI, which is a novel finding in this pre-clinical model of ARDS. One study previously observed that cryopreserved UC-MSCs significantly attenuated protein concentration in the lungs of rats with pneumonia [24]. Overall, these studies further support the use of cryopreserved MSCs in future clinical studies.

\subsection{UC-MSCs and BM-MSCs Comparably Modulate the Inflammatory Response}

The delivery of fresh, either BM-MSC or UC-MSC cell doses, significantly modified the inflammatory response to VILI as evidenced by resolved inflammatory cell infiltration in the injured lung, and cryopreservation did not hamper the efficacy of this MSC response. Similar observations were reported in rat models of E.coli-induced lung injury [8,9], but this is the first study to observe these findings in a VILI model.

The administration of MSCs in this animal model revealed a modified BAL cytokine profile. Freshly delivered BM-MSCs significantly relieved the release of IL-6, whereas UCMSCs did not. Interestingly, the cryopreserved cells did show a significant benefit. MSCs that are harvested on the same day, pooled, cryopreserved and then thawed for delivery, are likely to present as a more homogenous cell dose. Cryopreservation can therefore reduce the variability in MSC efficacy that can be attributed to either cell culture conditions or donor differences. BM-MSCs and UC-MSCs were previously observed to reduce BAL IL-6 in a rat pneumonia model [9]. Finally, fresh BM-MSCs, and either fresh or cryopreserved UC-MSCs, significantly reduced pro-inflammatory IL- $1 \beta$ release in the BAL. Overall, it is clear that neither the cell source nor cryopreservation can hinder the immunomodulatory 
effects of MSCs in this VILI animal model, and this agrees with previously published reports in other models of ARDS [8,9].

\subsection{UC-MSCs and BM-MSCs Comparably Restore Lung Structure}

Alveolar airspace and lung structure was significantly restored by MSC treatment, confirming that the MSCs from either BM or UC sources are equally efficacious, even after cryopreservation, in promoting resolution from injury in VILI. Similar observations in other preclinical models of ARDS were reported [8,24].

\section{Materials and Methods}

\subsection{Cell Culture}

A549/NF-kB-luciferase Cell Line Culture: NFkB inflammatory signaling is strongly involved in stretch-induced lung inflammation and injury, as well as ARDS development [25-27]. A549/NFkB-luciferase cells (Panomics, Fremont, CA, USA) were purchased as cryopreserved 3-passage culture and used at passages $4-10$. These cells have an integrated chromosomal luciferase reporter construct that is regulated by $N F \kappa B$, and are used for examining NFKB transcription factor activity in vitro. Breifly, A549 cells were co-transfected with a NFkB luciferase reporter plasmid and hygromycin-resistant plasmid, and then selected with hygromycin in culture. A TNF- $\alpha$ and luciferase assay was then used to select hygromycin-resistant cell clones. A549/NFKB-luciferase cells were passaged in RPMI-1640 growth medium (Sigma-Aldrich Ireland Ltd., Wicklow, Ireland) supplemented with $10 \%$ fetal bovine serum (FBS) (Sigma-Aldrich), 1\% penicillin G $(100 \mathrm{U} / \mathrm{mL}$ ) and streptomycin $(100 \mu \mathrm{g} / \mathrm{mL})$ solution (Sigma-Aldrich), $1 \%$ L-glutamine $(0.2 \mathrm{mg} / \mathrm{mL})$ (SigmaAldrich) and hygromycin ( $50 \mu \mathrm{g} / \mathrm{mL}$ final) (Roche Life Science, Penzberg, Germany). These cells were maintained in a humidified (95\%) tissue culture incubator saturated with a gas mixture containing $5 \% \mathrm{CO}_{2}$ and $20 \% \mathrm{O}_{2}$ in air at $37^{\circ} \mathrm{C}$. These cells were sub-cultured with $0.025 \%$ trypsin $/ 0.05$ mM EDTA (GIBCO ${ }^{\circledR}$, Invitrogen Corporation, Grand Island, NY, USA) and cryopreserved in CryoStor ${ }^{\mathrm{TM}}$ cell preservation medium (Sigma-Aldrich).

MSC and Dermal Fibroblast (DF) Isolation, Culture and Expansion: Human BMMSCs and UC-MSCs were isolated as previously described $[9,28]$ and used at passages 1-3 for all experiments. Briefly, for BM-MSCs, bone marrow aspirates were obtained from healthy donors after ethical consent and were subjected to Ficoll density gradient centrifugation (GE Healthcare, Chalfont St. Giles, UK). Mononuclear cells were selected by plastic adherence and cell surface marker expression. For UC-MSCs, umbilical cord tissue was ethically obtained after consent and physically disassociated. The tissue was then subjected to enzymatic breakdown in culture media containing Collagenase $1(2 \mathrm{mg} / \mathrm{mL}$ ) (Sigma Aldrich) at $37^{\circ} \mathrm{C}$ for less than one hour. The cells were filtered and a single cell suspension was obtained. Cells were selected by plastic adherence and surface marker expression. MSCs were cultured in Alpha Minimum Essential Eagle Medium plus Glutamax (MEM- $\alpha$ ) $\left(\mathrm{GIBCO}^{\circledR}\right)$ supplemented with $10 \%$ FCS, penicillin $\mathrm{G}(100 \mathrm{U} / \mathrm{mL})$ streptomycin $(100 \mu \mathrm{g} / \mathrm{mL})$ and FGF-1 (10 ng/mL) (PeproTech EC Ltd., London, UK). Cells were maintained in 95\% humidity, $5 \% \mathrm{CO}_{2}$ and $2 \% \mathrm{O}_{2}$ (hypoxia) at $37{ }^{\circ} \mathrm{C}$. These cells were sub-cultured with $0.025 \%$ trypsin- $0.05 / \mathrm{mM}$ EDTA and cryopreserved in CryoStor ${ }^{\mathrm{TM}}$ cell preservation medium $(200 \mu \mathrm{L}$ per 1 million cells). DFs were used as control cells. DFs were derived from skin punch biopsies ( $3 \mathrm{~mm}$ ), secured and cultured in 6-well plates (Sarstedt, Newton, NC, USA) until 80-90\% confluent, then expanded and maintained as described above. For animal dosing, cells were reconstituted in $1 \mathrm{~mL}$ of phosphate-buffered saline (PBS) (Sigma-Aldrich). Cryopreserved MSCs were stored for up to two months and cell viability after thawing was between $95-97 \%$ as determined by trypan blue exclusion.

Preparation of CM from DFs and MSCs: On day 1, the cells (passage 1-3) were seeded in a T175 tissue culture flask (Sarstedt) at $1 \times 10^{5} \mathrm{cells} / \mathrm{cm}^{2}$ in complete MEM- $\alpha$ medium (20 mLs). Forty-eight hours later (Day 3), the cells were washed three times in PBS solution before the addition of $20 \mathrm{mLs}$ of serum-free MEM- $\alpha$ medium. The CM was 
collected $48 \mathrm{~h}$ later (Day 5) and then stored at $-80^{\circ} \mathrm{C}$ for later use. The $\mathrm{CM}$ was discarded after two freeze-thaw cycles.

\subsection{Cyclic Mechanical Cell Stretch}

As previously described [25], A549/NFKB-luciferase cells were seeded to laminincoated 6-well Bioflex plates (Flexcell International, Burlington, NC, USA), mounted onto the Flexcell FX-4000T ${ }^{\circledR}$ Tension Plus ${ }^{\circledR}$ baseplate (Flexcell International) and subjected to $22 \%$ equibiaxial stretch at a frequency of $0.1 \mathrm{~Hz}$ for $120 \mathrm{~h}$. Non-stretched cells were used as control cells. Cells were maintained in their respective treatments for the entire $120 \mathrm{~h}$. Following stretch, the cells were harvested for luciferase and viability assays.

\subsection{Stretch Injury Assessment}

Luciferase Assay for NFKB Activity: Cells were harvested and pelleted then mixed with $50 \mu \mathrm{L}$ of SolarGlow SuperBright (Molecutools, Dublin, Ireland) luciferase assay substrate for $5 \mathrm{~min}$. Luminescence was measured in a VICTOR ${ }^{\mathrm{TM}} X$ plate reader (Perkin Elmer, Boston, MA, USA).

Viability Assay: Metabolic/mitochondrial activity was assessed by the thiazolyl blue tetrazolium bromide (MTT) (Sigma-Aldrich) assay, as previously described [29]. Briefly, $5 \%$ of intact harvested cells were incubated with $100 \mu \mathrm{L}$ of MTT solution $(100 \mu \mathrm{g} / \mathrm{mL}$ final concentration) in complete RPMI medium, in a tissue culture incubator $\left(5 \% \mathrm{CO}_{2}\right)$ for $2 \mathrm{~h}$. $50 \mu \mathrm{L}$ of DMSO was then added to each sample, and samples were kept at room temperature on an orbital mixer for $30 \mathrm{~min}$. Absorbance values were measured at $550 \mathrm{~nm}$.

\subsection{In Vitro Scratch Wounds}

A549/NFKB-luciferase cells were seeded at $1 \times 10^{5}$ cells per $\mathrm{cm}^{2}$ in a 24 -well plate (Sarstedt) and left to reach confluence for $48 \mathrm{~h}$. Single scratch wounds were generated with a $1 \mathrm{~mL}$ pipette tip (Sarstedt). The cells were washed with PBS and their respective treatments were added. Wound restitution was assessed over $48 \mathrm{~h}$ in scanned images using the edge finding function in image analysis software (GNU Image Manipulation Program).

\subsection{Rodent Model of Resolution Post Ventilation-Induced Lung Injury}

All work was approved by the Animal Care in Research Ethics Committee of the National University of Ireland Galway and conducted under license from the Health Products Regulatory Agency Ireland (License B100/4253). Specific-pathogen-free adult male Sprague Dawley rats (Charles River Laboratories, Kent, UK), weighing between 350-450 g, were used in all experiments.

Induction of VILI: As previously described [10], rats were anaesthetized with isoflurane gas and intravenous access was obtained via the tail vein. A laryngoscopy was performed and a $14 \mathrm{G}$ catheter (BD Insyte ${ }^{\circledR}$, Becton Dickinson Ltd., Oxfordshire, UK) was used to intubate the animal [30] for ventilation using a small animal ventilator (CWE SAR $830 \mathrm{AP}$; CWE Inc., Ardmore, PA, USA). Anaesthesia was maintained with repeated boli of Alfaxan ${ }^{\circledR}$ (Alfaxadone $0.9 \%(w / v)$ and alfadolone acetate $0.3 \%(w / v)$; Vétoquinol SA, Lure Cedex, France) and paralysis with cisatracurium besylate $0.5 \mathrm{mg} \cdot \mathrm{kg}^{-1}$ (GlaxoSmithKline, Dublin, Ireland). Following baseline ventilation, static compliance was measured and VILI was induced using the following ventilator settings: $\mathrm{Fi}_{\mathrm{O} 2}$ of $0.3, \mathrm{P}_{\text {insp }} 35 \mathrm{cmH}_{2} \mathrm{O}$, respiratory rate $18 \mathrm{~min}^{-1}$, and PEEP $0 \mathrm{cmH}_{2} \mathrm{O}$. Following development of severe VILI, as evidenced by a $50 \%$ decrease in respiratory static compliance, injurious ventilation was discontinued, and the animals were allowed to recover [8].

Experimental Design: Fifteen minutes post induction of VILI, animals were randomized to receive intravenous administrations of $1 \times 10^{7} \mathrm{MSCs} / \mathrm{kg}$ that were: (i) fresh BM-MSCs; (ii) fresh UC-MSCs; or (iii) thawed, cryopreserved UC-MSCs. Control animals received PBS solution and the extent of inflammation and injury resolution in all groups was measured at $24 \mathrm{~h}$. 


\subsection{Assessment of Lung Injury and Recovery}

In Vivo Assessment: At $24 \mathrm{~h}$ post induction of VILI, animals were re-anaesthetized as described above, intravenous access was obtained via tail vein, and a tracheostomy tube was inserted [10]. Following gaining intra-arterial access, anaesthesia was maintained with Alfaxan ${ }^{\circledR}$ and paralysis with cisatracurium besylate, and mechanical ventilation commenced. Arterial blood pressure, airway pressure, lung static compliance and arterial blood gas analyses were performed as previously described [8].

Ex Vivo Analyses: Following exsanguination under anesthesia, bronchoalveolar lavage (BAL) was performed, and BAL fluid differential leukocyte counts were completed. BAL concentrations of IL- 6 and IL- $1 \beta$, were determined using ELISA (R\&D Systems, Oxfordshire, UK) and BAL protein concentrations were also measured (Micro BCA; Pierce, IL, USA) as per the manufacturers guidelines. The left lung was isolated and fixed in $4 \%$ paraformaldehyde solution (PFA), sectioned, stained with haematoxylin/eosin and histologic lung damage determined using quantitative stereological techniques [31]. All ex vivo analyses were performed by blinded investigators.

\subsection{Statistical Analysis}

The distribution of the data was tested for normality using Kolmogorov-Smirnov tests. Data sets were analysed by a one-way analysis of variance (ANOVA), with a post hoc Student-Newman-Keuls test, for between group comparisons. Data are presented as mean \pm standard deviation (SD). A $p$ value of $<0.05$ was considered statistically significant. The power and sample size of the in vivo study was determined using estimations of variance for 2 key indices of ARDS (oxygenation and compliance) based on previously published data $[10,32]$ and the $G^{*}$ Power 3 program [33]. The study included $n=7$ animals per group and the power of the study was $>0.80$.

\section{Conclusions}

The study confirms that cryopreservation has no deleterious effect on the therapeutic efficacy of UC-MSCs in this injury and repair model, and this further supports the use of MSCs for different clinical presentations of ARDS. UC-MSCs represent a more readily available and cost-effective source of MSCs that is suitable for large-scale expansion and industrial production. The integrity and consistency of this cell product can be further maintained with cryopreservation without the loss of therapeutic efficacy, and signifies a huge advantage for the use of MSCs as a therapy for patients with ARDS.

Author Contributions: Conceptualization, M.S., D.O. and J.G.L.; methodology, S.H., H.G., J.B. and J.D.; data analysis, S.H., D.O. and J.G.L.; writing-original draft preparation S.H., H.G. and J.B.; writing - review and editing, S.H., D.O. and J.G.L.; funding acquisition, D.O. and J.G.L. All authors have read and agreed to the published version of the manuscript.

Funding: This work was supported by funding the European Research Council, Brussels, Belgium, under the Framework 7 Programme (ERC-2007-StG 207777 to J.G. Laffey), Science Foundation Ireland (16/FRL/3845 to J.G. Laffey; 14/TIDA/2291 to D. O'Toole), and the Health Research Board Ireland (HRA-POR-2015-1099 to D. O'Toole). All hMSCs were provided free of charge to the investigators by the Centre for Cell Manufacturing Ireland, Galway, Ireland and Tissue Regeneration Therapeutics Inc., Toronto, ON, Canada.

Institutional Review Board Statement: The study was approved by the Animal Care in Research Ethics Committee of the National University of Ireland Galway and conducted under license from the Health Products Regulatory Agency Ireland (License B100/4253, 08/02/2010).

Informed Consent Statement: Not applicable.

Data Availability Statement: Data is available from the authors upon reasonable request.

Conflicts of Interest: The authors declare no conflict of interest. 


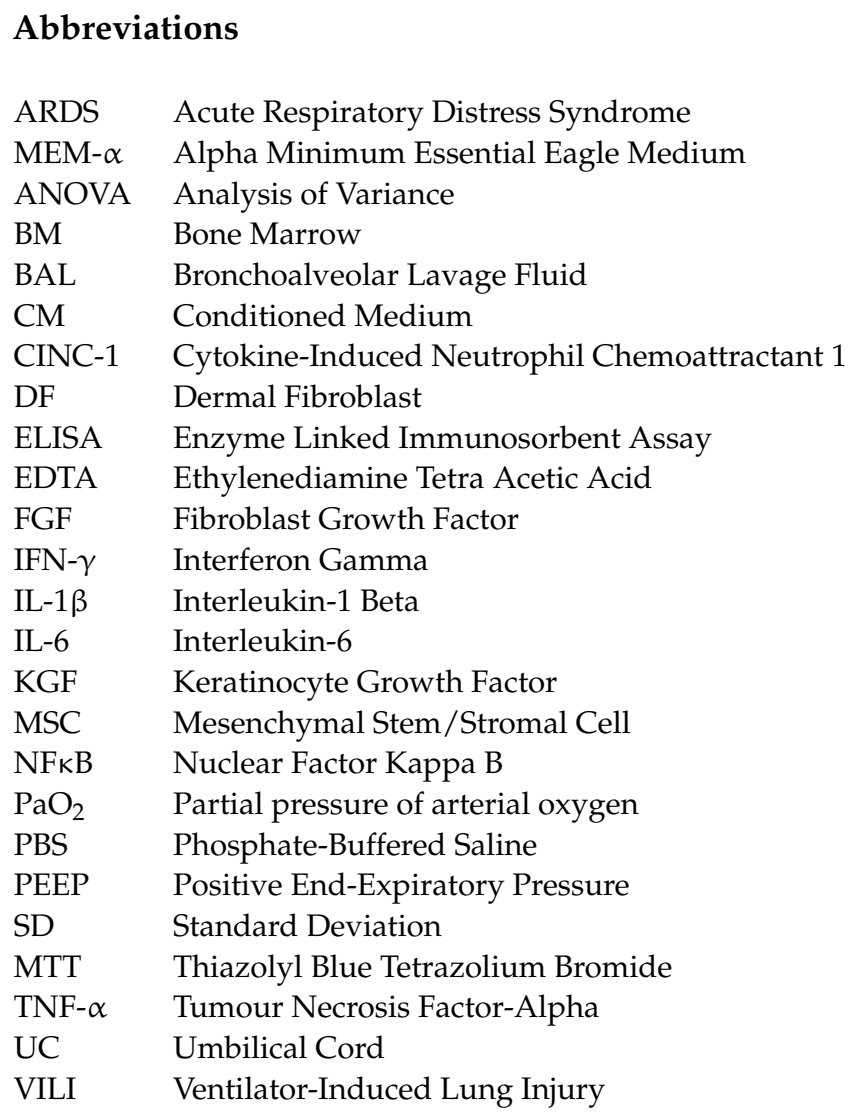

\section{References}

1. Ortiz, L.A.; Gambelli, F.; McBride, C.; Gaupp, D.; Baddoo, M.; Kaminski, N.; Phinney, D.G. Mesenchymal stem cell engraftment in lung is enhanced in response to bleomycin exposure and ameliorates its fibrotic effects. Proc. Natl. Acad. Sci. USA 2003, 100, 8407-8411. [CrossRef] [PubMed]

2. $\quad \mathrm{Xu}$, J.; Woods, C.R.; Mora, A.L.; Joodi, R.; Brigham, K.L.; Iyer, S.; Rojas, M. Prevention of endotoxin-induced systemic response by bone marrow-derived mesenchymal stem cells in mice. Am. J. Physiol. Lung Cell. Mol. Physiol. 2007, 293, L131-L141. [CrossRef] [PubMed]

3. Gupta, N.; Su, X.; Popov, B.; Lee, J.W.; Serikov, V.; Matthay, M.A. Intrapulmonary delivery of bone marrow-derived mesenchymal stem cells improves survival and attenuates endotoxin-induced acute lung injury in mice. J. Immunol. 2007, 179, 1855-1863. [CrossRef] [PubMed]

4. Mei, S.H.; Haitsma, J.J.; Dos Santos, C.C.; Deng, Y.; Lai, P.F.; Slutsky, A.S.; Liles, W.C.; Stewart, D.J. Mesenchymal stem cells reduce inflammation while enhancing bacterial clearance and improving survival in sepsis. Am. J. Respir. Crit. Care Med. 2010, 182, 1047-1057. [CrossRef]

5. Nemeth, K.; Leelahavanichkul, A.; Yuen, P.S.; Mayer, B.; Parmelee, A.; Doi, K.; Robey, P.G.; Leelahavanichkul, K.; Koller B.H.; Brown, J.M.; et al. Bone marrow stromal cells attenuate sepsis via prostaglandin E(2)-dependent reprogramming of host macrophages to increase their interleukin-10 production. Nat. Med. 2009, 15, 42-49. [CrossRef] [PubMed]

6. van Haaften, T.; Byrne, R.; Bonnet, S.; Rochefort, G.Y.; Akabutu, J.; Bouchentouf, M.; Rey-Parra, G.J.; Galipeau, J.; Haromy, A.; Eaton, F.; et al. Airway delivery of mesenchymal stem cells prevents arrested alveolar growth in neonatal lung injury in rats. Am. J. Respir. Crit. Care Med. 2009, 180, 1131-1142. [CrossRef] [PubMed]

7. Aslam, M.; Baveja, R.; Liang, O.D.; Fernandez-Gonzalez, A.; Lee, C.; Mitsialis, S.A.; Kourembanas, S. Bone marrow stromal cells attenuate lung injury in a murine model of neonatal chronic lung disease. Am. J. Respir. Crit. Care Med. 2009, 180, 1122-1130. [CrossRef] [PubMed]

8. Devaney, J.; Horie, S.; Masterson, C.; Elliman, S.; Barry, F.; Brien, T.; Curley, G.F.; O’Toole, D.; Laffey, J.G. Human mesenchymal stromal cells decrease the severity of acute lung injury induced by E. coli in the rat. Thorax 2015, 70, 625. [CrossRef]

9. Horie, S.; Masterson, C.; Brady, J.; Loftus, P.; Horan, E.; O’Flynn, L.; Elliman, S.; Barry, F.; O’Brien, T.; Laffey, J.G.; et al. Umbilical cord-derived CD362(+) mesenchymal stromal cells for E. coli pneumonia: Impact of dose regimen, passage, cryopreservation, and antibiotic therapy. Stem Cell Res. Ther. 2020, 11, 116. [CrossRef] [PubMed]

10. Horie, S.; Gaynard, S.; Murphy, M.; Barry, F.; Scully, M.; O’Toole, D.; Laffey, J.G. Cytokine pre-activation of cryopreserved xenogeneic-free human mesenchymal stromal cells enhances resolution and repair following ventilator-induced lung injury potentially via a KGF-dependent mechanism. Intensive Care Med. Exp. 2020, 8, 8. [CrossRef] 
11. Curley, G.F.; Ansari, B.; Hayes, M.; Devaney, J.; Masterson, C.; Ryan, A.; Barry, F.; O’Brien, T.; Toole, D.O.; Laffey, J.G. Effects of intratracheal mesenchymal stromal cell therapy during recovery and resolution after ventilator-induced lung injury. Anesthesiology 2013, 118, 924-932. [CrossRef] [PubMed]

12. Lee, J.W.; Krasnodembskaya, A.; McKenna, D.H.; Song, Y.; Abbott, J.; Matthay, M.A. Therapeutic effects of human mesenchymal stem cells in ex vivo human lungs injured with live bacteria. Am. J. Respir. Crit. Care Med. 2013, 187, 751-760. [CrossRef] [PubMed]

13. Horie, S.; McNicholas, B.; Rezoagli, E.; Pham, T.; Curley, G.; McAuley, D.; O'Kane, C.; Nichol, A.; dos Santos, C.; Rocco, P.R.M.; et al. Emerging pharmacological therapies for ARDS: COVID-19 and beyond. Intensive Care Med. 2020, 46, 2265-2283. [CrossRef] [PubMed]

14. Galipeau, J. The mesenchymal stromal cells dilemma-does a negative phase III trial of random donor mesenchymal stromal cells in steroid-resistant graft-versus-host disease represent a death knell or a bump in the road? Cytotherapy 2013, 15, 2-8. [CrossRef]

15. Digirolamo, C.M.; Stokes, D.; Colter, D.; Phinney, D.G.; Class, R.; Prockop, D.J. Propagation and senescence of human marrow stromal cells in culture: A simple colony-forming assay identifies samples with the greatest potential to propagate and differentiate. Br. J. Haematol. 1999, 107, 275-281. [CrossRef]

16. De Witte, S.F.H.; Lambert, E.E.; Merino, A.; Strini, T.; Douben, H.J.C.W.; O’Flynn, L.; Elliman, S.J.; de Klein, A.J.E.M.M.; Newsome, P.N.; Baan, C.C.; et al. Aging of bone marrow- and umbilical cord-derived mesenchymal stromal cells during expansion. Cytotherapy 2017, 19, 798-807. [CrossRef] [PubMed]

17. Hua, J.; Gong, J.; Meng, H.; Xu, B.; Yao, L.; Qian, M.; He, Z.; Zou, S.; Zhou, B.; Song, Z. Comparison of different methods for the isolation of mesenchymal stem cells from umbilical cord matrix: Proliferation and multilineage differentiation as compared to mesenchymal stem cells from umbilical cord blood and bone marrow. Cell Biol. Int. 2013, 38, 198-210. [CrossRef]

18. Fong, C.Y.; Gauthaman, K.; Cheyyatraivendran, S.; Lin, H.D.; Biswas, A.; Bongso, A. Human umbilical cord Wharton's jelly stem cells and its conditioned medium support hematopoietic stem cell expansion ex vivo. J. Cell Biochem. 2012, 113, 658-668. [CrossRef]

19. Mattar, P.; Bieback, K. Comparing the Immunomodulatory Properties of Bone Marrow, Adipose Tissue, and Birth-Associated Tissue Mesenchymal Stromal Cells. Front. Immunol. 2015, 6, 560. [CrossRef] [PubMed]

20. Jin, H.J.; Bae, Y.K.; Kim, M.; Kwon, S.-J.; Jeon, H.B.; Choi, S.J.; Kim, S.W.; Yang, Y.S.; Oh, W.; Chang, J.W. Comparative Analysis of Human Mesenchymal Stem Cells from Bone Marrow, Adipose Tissue, and Umbilical Cord Blood as Sources of Cell Therapy. Int. J. Mol. Sci. 2013, 14, 17986-18001. [CrossRef]

21. François, M.; Copland, I.B.; Yuan, S.; Romieu-Mourez, R.; Waller, E.K.; Galipeau, J. Cryopreserved mesenchymal stromal cells display impaired immunosuppressive properties as a result of heat-shock response and impaired interferon- $\gamma$ licensing. Cytotherapy 2012, 14, 147-152. [CrossRef]

22. Hoogduijn, M.J.; de Witte, S.F.; Luk, F.; van den Hout-van Vroonhoven, M.C.; Ignatowicz, L.; Catar, R.; Strini, T.; Korevaar, S.S.; van, I.W.F.; Betjes, M.G.; et al. Effects of Freeze-Thawing and Intravenous Infusion on Mesenchymal Stromal Cell Gene Expression. Stem Cells Dev. 2016, 25, 586-597. [CrossRef]

23. Curley, G.F.; Hayes, M.; Ansari, B.; Shaw, G.; Ryan, A.; Barry, F.; O’Brien, T.; O’Toole, D.; Laffey, J.G. Mesenchymal stem cells enhance recovery and repair following ventilator-induced lung injury in the rat. Thorax 2012, 67, 496-501. [CrossRef]

24. Curley, G.F.; Jerkic, M.; Dixon, S.; Hogan, G.; Masterson, C.; O’Toole, D.; Devaney, J.; Laffey, J.G. Cryopreserved, Xeno-Free Human Umbilical Cord Mesenchymal Stromal Cells Reduce Lung Injury Severity and Bacterial Burden in Rodent Escherichia coli-Induced Acute Respiratory Distress Syndrome. Crit. Care Med. 2017, 45, e202-e212. [CrossRef] [PubMed]

25. Horie, S.; Ansari, B.; Masterson, C.; Devaney, J.; Scully, M.; O’Toole, D.; Laffey, J.G. Hypercapnic acidosis attenuates pulmonary epithelial stretch-induced injury via inhibition of the canonical NF-кB pathway. Intensive Care Med. Exp. 2016, 4, 8. [CrossRef]

26. Liu, Y.Y.; Liao, S.K.; Huang, C.C.; Tsai, Y.H.; Quinn, D.A.; Li, L.F. Role for nuclear factor-kappaB in augmented lung injury because of interaction between hyperoxia and high stretch ventilation. Transl. Res. 2009, 154, 228-240. [CrossRef]

27. Schwartz, M.D.; Moore, E.E.; Moore, F.A.; Shenkar, R.; Moine, P.; Haenel, J.B.; Abraham, E. Nuclear factor-kappa B is activated in alveolar macrophages from patients with acute respiratory distress syndrome. Crit. Care Med. 1996, 24, 1285-1292. [CrossRef]

28. Mennan, C.; Garcia, J.; Roberts, S.; Hulme, C.; Wright, K. A comprehensive characterisation of large-scale expanded human bone marrow and umbilical cord mesenchymal stem cells. Stem Cell Res. Ther. 2019, 10, 99. [CrossRef] [PubMed]

29. Morgan, D.M. Tetrazolium (MTT) assay for cellular viability and activity. Methods Mol. Biol. 1998, 79, 179-183. [CrossRef] [PubMed]

30. Kastl, S.; Kotschenreuther, U.; Hille, B.; Schmidt, J.; Gepp, H.; Hohenberger, W. Simplification of rat intubation on inclined metal plate. Adv. Physiol. Educ. 2004, 28, 29-32. [CrossRef]

31. Laffey, J.G.; Honan, D.; Hopkins, N.; Hyvelin, J.M.; Boylan, J.F.; McLoughlin, P. Hypercapnic acidosis attenuates endotoxininduced acute lung injury. Am. J. Respir. Crit. Care Med. 2004, 169, 46-56. [CrossRef]

32. Hayes, M.; Masterson, C.; Devaney, J.; Barry, F.; Elliman, S.; O’Brien, T.; O'Toole, D.; Curley, G.F.; Laffey, J.G. Therapeutic efficacy of human mesenchymal stromal cells in the repair of established ventilator-induced lung injury in the rat. Anesthesiology 2015, 122, 363-373. [CrossRef] [PubMed]

33. Faul, F.; Erdfelder, E.; Lang, A.G.; Buchner, A. G*Power 3: A flexible statistical power analysis program for the social, behavioral, and biomedical sciences. Behav. Res. Methods 2007, 39, 175-191. [CrossRef] 